\title{
ELETROQUÍMICA: CONSTRUÇÃO DE PILHAS NO EXPERIMENTO UTILIZANDO O ZINCO E MATERIAIS CASEIROS
}

(*): LOPES, B. G. (IFRN); LOPES, S. R. G (IFRN) ; SOUSA, R. L. (IFRN) ; BEZERRA, D. P. (IFRN)

\section{RESUMO}

A eletroquímica é um seguimento da Química que estuda o fenômeno de transferência de elétrons entre diferentes substâncias para converter energia química em energia elétrica. O uso de materiais caseiros é um método simples e de muita importância para realização dos experimentos que além de ter a facilidade ao alcance de todos, ainda contribui numa aprendizagem simples e objetiva, como mostra na metodologia deste trabalho, de como ocorrem as reações de oxirredução, que também estão presentes no cotidiano, utilizando materiais de baixo custo e de fácil acesso. No procedimento, utilizaram-se copos de plásticos, placas de zinco e cobre, e fez o teste adicionando água sanitaria nos copos, e mediu-se a voltagem. Acrescentou-se sal e mediu-se a voltagem novamente. Logo, foram construídas 05 pilhas usando o mesmo procedimento. Conseqüentemente, foram utilizadas duas lâmpadas leds para testar a existência de corrente elétrica. Por último, utilizou um motor de 5 volts ligado as 6 pilhas ligadas em série. Os resultados foram satisfatórios, pois quando se inseriu as duas lâmpadas do tipo led no sistema, foi observada a iluminação na forma de pisca-pisca. E por fim, com a inserção de um motor giratório de $5 \mathrm{~V}$, foi observado seu pleno funcionamento.

\section{ELECTROCHEMICAL: BATTERY CONSTRUCTION IN EXPERIMENT USING ZINC AND HOMEMADE MATERIALS}

\begin{abstract}
Electrochemical is a segment of chemistry that studies the electron transfer phenomenon between different substances to convert chemical energy into electrical energy. The use of homemade materials is a simple and very important for the experiments that besides having the facility available to all, also contributes a simple and objective learning, as shown in the methodology of this study, how occur the reactions of redox which are also present in everyday life, using low-cost materials and easy access. In the procedure, they used plastic cups, zinc and copper plates, and auditioned adding bleach in
\end{abstract}

the cups, and the voltage was measured. Salt is added and the voltage was measured again. Therefore, batteries 05 are built using the same procedure. Consequently, we used two LED lamps to test the existence of electric current. Finally, we used a 5 volt motor attached the 6 batteries connected in series. The results were satisfactory, because when you entered the two lamps LED type in the system, there was the lighting in the form of flasher. Finally, with the insertion of a rotary motor $5 \mathrm{~V}$ was observed its full operation.

KEY-WORDS: electrochemistry, experiments, homemade materials. 


\section{ELETROQUÍMICA: CONSTRUÇÃO DE PILHAS NO EXPERIMENTO UTILIZANDO O ZINCO E MATERIAIS CASEIROS}

\section{INTRODUÇÃO}

A necessidade de energia é uma demanda cada vez maior nos últimos anos. A industrialização e informatização de sistemas produtores elevou ainda mais a necessidade de fontes energéticas. Determina-se energia como a capacidade que os materiais ou aparelhos têm de realizar trabalho. O aparecimento da energia, portanto, pode ocorrer vários fenômenos reais, podendo adquirir vários sentidos, como movimento, força, trabalho, calor, luz, eletricidade entre outros. Extremamente, essas revelações de energia foram observadas desde a antiguidade, porém, esses acontecimentos eram analisados involuntariamente, tendo vista que entre eles não existiam uma formação cientificamente. No início da revolução industrial a produção era através de máquinas a vapor, e a principal fonte de energia era o carvão. Com isso, consequentemente houve vários avanços na indústria trazendo vários benefícios para a sociedade como aplicações de iluminações, tecnologia e comunicação. O referente estudo foi desenvolvido com o objetivo de buscar novos conhecimentos na área da Química, utilizando a energia como assunto de importância no universo em que vivemos e de grande interesse para a sociedade de modo geral.

\section{MATERIAIS E MÉTODOS}

Para iniciar o experimento foram utilizados materiais caseiros de fácil acesso e de baixo custo que incluíram 01 multímetro, 06 copos de plásticos de $200 \mathrm{~mL}, 06$ placas metálicas de zinco com $13 \mathrm{~cm} \times 3,5 \mathrm{~cm}$; 06 peças de fio de cobre rígido com $13 \mathrm{~cm} \times$ 2,5mm; 06 peças de fio flexível de cobre com 10cm; 06 peças de fio de cobre flexível com dimensões de $10 \mathrm{~cm}$ por $1,5 \mathrm{~mm}, 20 \mathrm{~cm}$ de fio de cobre de 1,5 mm de espessura, 02 lâmpadas tipo leds de 2 volts, 01 motor de 5 volts. Os equipamentos necessários utilizados na construção das pilhas constituíram 01 martelo, 01 prego grande, 01 alicate, lixa, 01 colher (para medição). Os reagentes para cada pilha foram água (200 $\mathrm{ml}), 01$ colher de (sopa) de sal, 0,5 ml de água sanitária.

\subsection{MÉTODO}

A metodologia foi iniciada com pesquisa em busca de novos conhecimentos sobre a energia na área da eletroquímica e foi observado um experimento de baterias feito com latinha de refrigerante. Thenório, (2013). Então, resolveu-se fazer o teste com essas latinhas de refrigerantes usando o mesmo método que havia pesquisado e o resultado não apresentou-se como o reportado. Seguiu-se então, para realizar algumas modificações sem que pudesse alterar as reações e que com essa substituição o resultado fosse similar ao reportado. Thenório,(2013) . Foi substituído a latinha por copos plásticos, utilizando o metal Zinco no lugar do alumínio permanecendo o metal cobre. Com essa modificação, espera-se que obtivesse uma potência maior. 
No procedimento, utilizaram-se o copo plástico e adicionou a placa de zinco (Zn) como ânodo, pólo negativo, e o cobre $(\mathrm{Cu})$ como cátodo, pólo positivo, e fez o teste só com a água sanitária dentro dos copos, que para que se fizesse a medição de voltagem foi utilizado o multímetro. Para que houvesse o aumento da voltagem, acrescentou-se o sal e água sanitária e mediou-se a voltagem novamente com o multímetro. Em seguida, foi construído 05 pilhas usando o mesmo procedimento, e feito a ligação em série conectando o fio da pilha do pólo positivo com o pólo negativo da outra pilha, seguindo sucessivamente com todas as pilhas concluindo as ligações, foi realizado outra medição com o multímetro. Logo após foi utilizado duas lâmpadas leds para testar a existência de corrente elétrica. Por último, utilizou um motor de 5 volts ligado as 6 pilhas ligadas em série.

\section{RESULTADOS E DISCUSSÕES}

Os resultados das diferenças de potencial (ddp) para os reagentes utilizados, segundo os procedimentos metodológicos, seguem descritos na tabela 1 . 0 valor inicial, com apenas água sanitária, foi de $0,90 \mathrm{~V}$. Esse valor sofreu alteração com a adição de sal de cozinha, atingindo $0,94 \mathrm{~V}$. A ddp ficou realmente maior, com 5,27 V, quando formou-se uma bateria com 6 pilhas contadas entre se (ver figura 1).

Tabela 1 - Resultados dos valores de ddp dos procedimentos usados.

\begin{tabular}{|c|c|}
\hline Reagentes & Diferença de Potencial (Volts) \\
\hline Água Sanitária & 0,90 \\
\hline Água Sanitária + Sal & 0,94 \\
\hline Água Sanitária + Sal em 6 pilhas em série & 5,27 \\
\hline
\end{tabular}

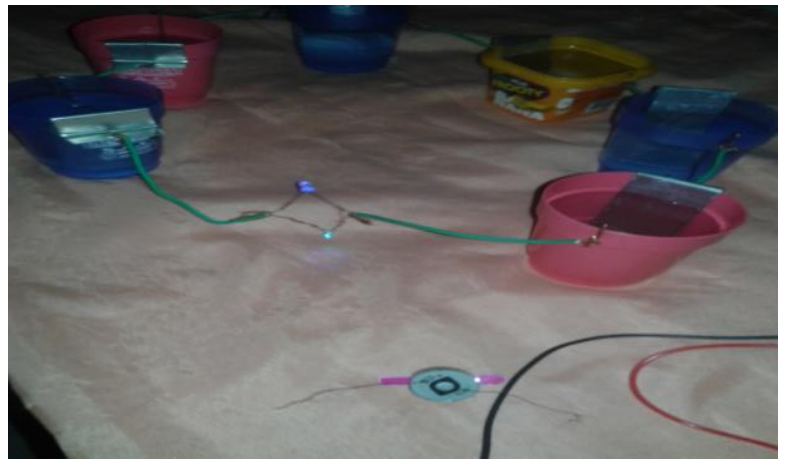

Figura 1 - Referente a montagem de pilhas com materiais caseiros.

Para os procedimentos adotados segundo o procedimento metodológico, os resultados estão expostos na tabela 2. Quando se inseriu as duas lâmpadas do tipo led no sistema, foi observado a iluminação na forma de pisca-pisca (ver na figura 2a). Por fim, com a inserção de um motor giratório de $5 \mathrm{~V}$, foi observado seu pleno funcionamento (ver figura $2 b$ ). 
Tabela 2 - Resultados dos procedimentos adotados conforme procedimento usado.

\begin{tabular}{|c|c|}
\hline Procedimentos & Resultado \\
\hline Lâmpadas Led & Ligadas em forma de pisca-pisca \\
\hline Motor de 5 V & Movimento giratório (ligado) \\
\hline
\end{tabular}

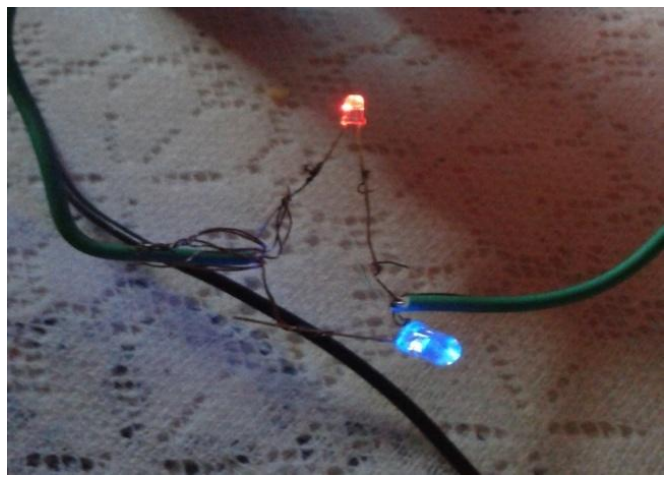

(a)

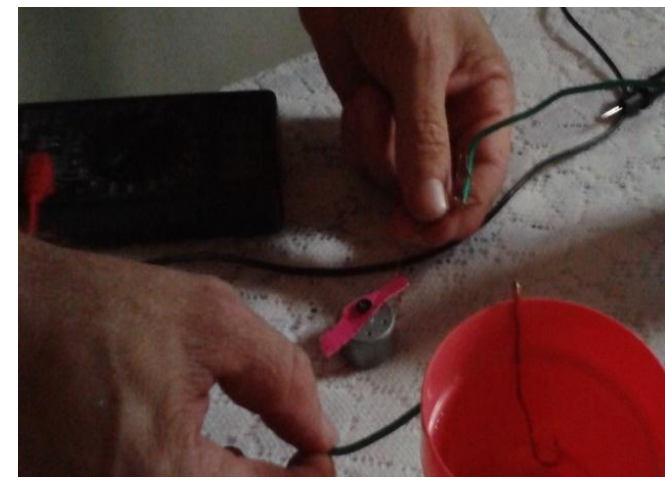

(b)

Figura 2. Referente (a) às duas lâmpadas do tipo led e (b) ao motor 5 volı

\section{CONCLUSÃO}

Mediante estudos, observações e experimentos conclui-se ainda nos dias de hoje, as descobertas são constantes e de grande interesse por parte tecnológica, em busca de energia mais sustentável, mais saudável, sem agredir o meio ambiente e dando mais comodidade à sociedade. Esse experimento é bastante simples do ponto de vista tecnológico, contudo bastante importante para o processo de desenvolvimento inicial do conhecimento sobre o tema de eletroquímica.

\section{AGRADECIMENTOS}

Os autores agradecem ao Instituto Federal de Educação, Ciência e Tecnologia do Rio Grande do Norte - IFRN, Campus Ipanguaçu pela disponibilização do espaço cedido e ao Conselho Nacional de Desenvolvimento Científico e Tecnológico (CNPq) pelas bolsas concedidas e apoio financeiro para realização do projeto.

\section{REFERÊNCIAS}

FONSECA. Martha Reis Marques da. Completamente química: físico- química. São Paulo: FTD, 2001.

THENÓRIO, Iberê. Bateria de Latinha de Alumínio (Experiência de Química). Disponível em: < http://manualdomundo.com.br >Acesso em: 15 de Mar 2016. 